\title{
Temperature sensor module for groundwater flow detection around borehole heat exchangers
}

\author{
Alexander Michalski ${ }^{*}$ and Norbert Klitzsch
}

*Correspondence:
AMichalski@eonerc.
rwth-aachen.de
Applied Geophysics
and Geothermal Energy,
E.ON ERC, RWTH Aachen
University, Aachen, Germany

${ }^{*}$ Correspondence: AMichalski@eonerc. Applied Geophysic and Geothermal Energy, University, Aachen, Germany

\begin{abstract}
We present a temperature sensor module (TSM) for detecting the groundwater flow velocity and direction in the vicinity of a borehole heat exchanger (BHE). We demonstrate the method for double U-tube BHEs, which can also be applied to coaxial BHEs. TSMs can be installed together with a BHE to monitor the temperature distribution in the horizontal plane of a BHE. They consist of 16 digital temperature sensors equally distributed on two concentric rings and a compass, which provides the TSM orientation. While the eight sensors located on the inner ring mainly map the temperatures of the inlet and outlet tubes, the temperatures measured on the outer ring are influenced by advective heat transport due to groundwater flow. We study the sensitivity of the TSM to groundwater flow by numerical simulations and suggest a method for deriving both the groundwater flow velocity and direction. Moreover, we designed a TSM prototype and tested it in a sandbox experiment. This test confirmed the operational principle of the TSM and the method for determining the groundwater flow velocity and direction. The digital temperature sensors used in the TSM prototype resolve temperature changes down to $0.02 \mathrm{~K}$. Both the numerical simulations and the experimental measurements show that such a temperature resolution enables the detection of groundwater flow velocities above $10^{-7} \mathrm{~m} \mathrm{~s}^{-1}\left(>30 \mathrm{~m} \mathrm{a}^{-1}\right)$.
\end{abstract}

Keywords: Borehole heat exchanger, BHE, Groundwater, Numerical simulation, EGRT, Enhanced geothermal response test

\section{Background}

The long-term efficiency of borehole heat exchanger (BHE) fields can be affected by groundwater flow (Fütterer and Constantin 2014; Fütterer et al. 2011; Lazzari et al. 2010). The advective transport of heat can influence neighboring BHEs and thus reduce the heating and cooling power capacity of the BHE field (Diao et al. 2004). To maintain a highly efficient BHE field, it can be necessary to optimize the operation of the entire BHE field or parts of the BHE field by individual control of the BHE (Hecht-Mendez et al. 2013). The thermal storage capacity of a borehole heat exchanger field strongly depends on the thermal interaction of the BHEs. Claesson and Eskilson (1988) showed that the BHE field geometry and the thermal interaction between the BHEs depend on groundwater flow. In this sense, knowledge about groundwater flow is highly recommended.

(c) The Author(s) 2018. This article is distributed under the terms of the Creative Commons Attribution 4.0 International License (http://creativecommons.org/licenses/by/4.0/), which permits unrestricted use, distribution, and reproduction in any medium, provided you give appropriate credit to the original author(s) and the source, provide a link to the Creative Commons license, and indicate if changes were made. 
There are many types of groundwater flow measurements in boreholes, which differ in their underlying measurement principles (Guaraglia 2014). The most common methods utilize tracers, heat sources (Pitschel 2001) or optical methods and measure the tracer concentration (Schön 1996), temperature distribution or particle flow velocity (Schöttler 2000), respectively. Morgenstern (2005) gives an extensive compilation of groundwater flow measurement methods. All these methods consist of measurements taken in open wells where absent rock changes the natural flow field (Bergmann 1970). Hence, the real groundwater flow is not directly measured, but is obtained after correction of the borehole influence (Klotz 1977). A method for detecting groundwater flow, which can also be applied when a BHE is installed in the borehole, is the enhanced geothermal response test (EGRT), (Luo et al. 2015). Classically, thermal response tests (TRT) are used to determine the influence of the underground properties and additional groundwater effect on the effectivity of BHE (Wagner et al. 2012). While the TRT only provides an effective thermal conductivity for the underground, the EGRT allows a depth resolved vertical distribution of the apparent thermal conductivity near the BHE. Groundwater flow causes high apparent thermal conductivities above the typical thermal conductivities for the respective lithology or above the values measured in the laboratory (Heidinger et al. 2004), i.e., high apparent conductivities indicate groundwater flow. In this way, aquifers can be localized and the BHE or BHE field can be characterized more precisely (Luo et al. 2015). However, EGRT data cannot be used to determine flow direction and velocity.

Here, we present a new concept for determining the groundwater flow rate and direction using horizontal temperature sensor rings installed inside a BHE, which is published as a German patent (DE102016203865). We call these two concentric rings with eight temperature sensors at each ring the temperature sensor module (TSM). This temperature sensor module (TSM) makes it possible to detect the temperature field distribution inside and in the direct vicinity of a real BHE. A BHE in a non-groundwater flow case shows a nearly symmetrical temperature field, which is proportional to the distance from the BHE to the monitoring point. Introducing advective heat transport through groundwater flow causes a distortion in the temperature distribution and hence a difference in temperature with a maximum value in the flow direction. Monitoring the radial temperature distribution on the surface of the borehole heat exchanger allows determination of the flow direction and the flow strength. Figure 1 shows a schematic cross section of the BHE and the TSM positions. The sensor rings are mounted around the BHE inlet and outlet tubes. While the inner ring, with a diameter of $90 \mathrm{~mm}$, is close to the BHE tubes, the outer ring (diameter of $150 \mathrm{~mm}$ ) is on the surface of the BHE. The temperatures measured by the inner sensors mainly depend on their position relative to the inlet and outlet tubes. Thus, these measurements can be used to determine the orientation of the TSM relative to the BHE. In contrast to the inner sensors, the outer sensor temperatures depend mainly on the thermal properties of the surrounding material. However, we expect that they will also be influenced by advective heat transport due to groundwater flow. We prove our assumption by numerical simulations of the heat and mass transport in a 2D plane perpendicular to the BHE using SHEMAT-Suite (Rath et al. 2006), which we introduce in "Methods" section. 


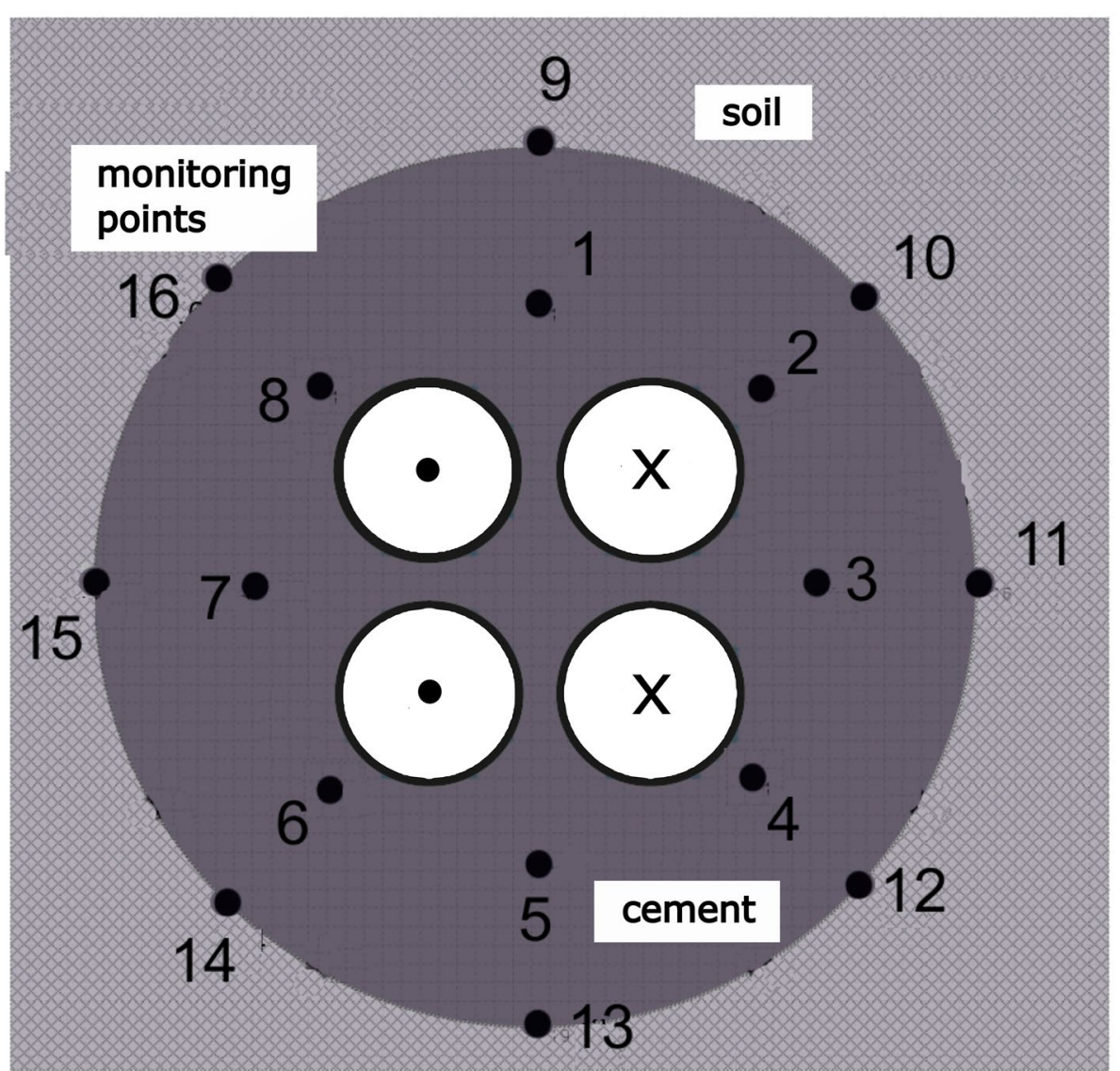

Fig. 1 Cross section of a BHE equipped with 16 temperature sensors (numbered 1-16) in a TSM. The outlet (bullet) and inlet (times) tubes of the BHE are enclosed by the inner sensors. The outer sensors are located on the surface of the BHE

The simulation results serve to layout the temperature sensor module. Additionally, we present a TSM prototype used in a sandbox experiment to verify the concept. First, experimental data and forward simulation of the prototype that has been tested in a sandbox experimental environment are subsequently analyzed and used to assess the TSM concept.

\section{Methods}

Basics

We use SHEMAT-Suite, a finite-difference simulator for heat and mass transport in porous media based on the code of Processing SHEMAT (Clauser 2003). The combined flow and heat transport equations (Bear 1988) are solved on a Cartesian 2D grid. Water flow is calculated by:

$$
\nabla \cdot\left[\frac{\rho_{\mathrm{w}} g k}{\mu}\left(\nabla h+\rho_{\mathrm{r}} \nabla z\right)\right]+Q=S_{\mathrm{s}} \frac{\partial h}{\partial t}
$$

where $\rho_{\mathrm{w}}$ is the density of water $\left[\mathrm{kg} \mathrm{m}^{-3}\right], \mu$ is the dynamic viscosity of water $\left[\mathrm{kg}\left(\mathrm{m} \mathrm{s}^{-1}\right]\right.$, $g$ is gravity $\left[\mathrm{m} \mathrm{s}^{-2}\right], k$ is permeability $\left[\mathrm{m}^{2}\right], h$ is the hydraulic head $[\mathrm{m}], z$ is the vertical 

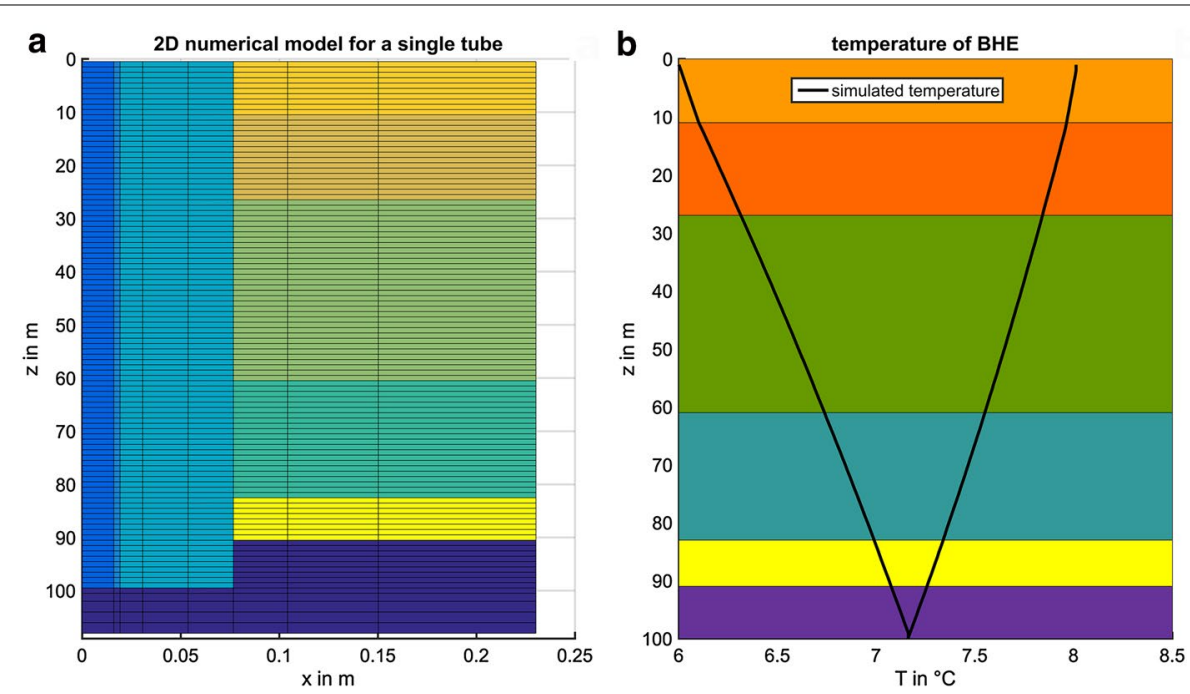

Fig. 2 2D model of the BHE tube (a) and simulation of the calculated inlet and outlet tube temperatures as a function of depth (b). The colors denote units with different geophysical properties

coordinate in space $[\mathrm{m}]$, and $\rho_{\mathrm{r}}=\left(\rho_{\mathrm{f}}-\rho_{0}\right) \rho_{0}^{-1}$ describes the pressure-dependent relative change in water density to a reference density $\rho_{0}$. $Q[\mathrm{~W}]$ is a source term, and $S_{\mathrm{s}}$ is the specific storage coefficient $\left[\mathrm{s}^{-1}\right]$.

As an analog to the flow equation (Eq. 1) taken from the mass balance equation, the heat transport equation may be derived from Fourier's Law and the energy balance equation (Incropera 2011; Carslaw and Jaeger 1959):

$$
\nabla \cdot\left(\rho_{\mathrm{W}} c_{\mathrm{W}} T v-\lambda \nabla T\right)+H=(p c)_{\mathrm{e}} \frac{\partial T}{\partial t}
$$

where $T$ is the temperature $\left[{ }^{\circ} \mathrm{C}\right], c_{\mathrm{w}}$ is the specific heat capacity of water $\left[\mathrm{J}(\mathrm{kg} \mathrm{K})^{-1}\right]$, and $H$ is a heat source term $\left[\mathrm{W} \mathrm{m}{ }^{-3}\right] . \lambda_{\mathrm{e}}\left[\mathrm{W} \mathrm{m}^{-1} \mathrm{~K}^{-1}\right]$ is the effective thermal conductivity of the fluid-filled matrix, and $c_{\mathrm{w}}$ and $c_{\mathrm{e}}$ are the volumetric heat capacities of water and the fluid-saturated porous medium $\left[\mathrm{J} \mathrm{m}^{-3} \mathrm{~K}^{-1}\right]$, respectively. $v$ is the Darcy velocity $\left[\mathrm{m} \mathrm{s}^{-1}\right]$. Two 2D models are used in this work to simulate the temperature distribution in a BHE. In the first model, we want to determine the temperature of the working fluid in the BHE. Subsequently, we use the obtained inlet tube and outlet tube temperatures to simulate the temperature distribution in a horizontal plane with the BHE in the center of the model (similar to Fig. 1). With this model, we study the effect of groundwater flow on the temperature distribution in the vicinity of the BHE.

\section{Simulation of the working fluid temperature in the BHE}

To calculate the working fluid temperature along the BHE, we use a simplified one-tube model of a single inlet tube in two ways. First, we simulate the temperature distribution of the working fluid in the inlet tube. Second, we simulate the temperature of the working fluid for the back leading outlet tube using the previously simulated temperature at the bottom of the inlet tube as the input. We consider a 100-m-long tube with a $32 \mathrm{~mm}$ diameter. In Fig. 2a, a section of the 2D model property units is shown, where the 
colors represent the units with equal physical properties. The blue units on the left side represent the tube and cement of the BHE. The rotation symmetric model consists of $30 \times 120 \times 1$ cells. For a realistic description of the pipe, the cells that simulate the pipe are $16 \mathrm{~mm}$ thick and $1 \mathrm{~m}$ long. In addition, the pipe wall and the backfilling cement are also resolved. In the $z$-direction, the pipe is divided into 100 equidistant 1 -m-long sections, and the whole model is extended to $150 \mathrm{~m}$ depth to avoid boundary effects. Six geological layers are considered. We use data from the E.ON ERC BHE field, which is located in Aachen (Pechnig and Mottaghy 2012). The colors in Fig. 2a, b denote different layers with varying parameters for porosity and thermal conductivity (Table 1).

The simulated temperature along the inlet and outlet tubes is shown in Fig. 2b. With an inlet temperature of $6{ }^{\circ} \mathrm{C}$ and a flow rate of $450 \mathrm{~cm}^{3} \mathrm{~s}^{-1}$, we calculated an outlet temperature of $8{ }^{\circ} \mathrm{C}$, which matched the temperature of $8.1^{\circ} \mathrm{C}$ measured at the outlet of the BHE in our field fairly well. Hence, we assume that the obtained temperature profiles of the inlet and outlet tubes are realistic. In the first $10 \mathrm{~m}$, the temperature gradient was lower than that in the other layers (thermal conductivity of layers two to six in $\mathrm{W} \mathrm{m}^{-1} \mathrm{~K}^{-1}: 2.6,2.83,3.01,2.87$, and 2.92) due to the smaller thermal conductivity of $1.2 \mathrm{~W} \mathrm{~m}^{-1} \mathrm{~K}^{-1}$. At a depth of approximately 80-90 m, the EGRT (enhanced geothermal response test) provided unexpectedly high apparent thermal conductivities of $3.4 \mathrm{~W} \mathrm{~m}^{-1} \mathrm{~K}^{-1}$. As they exceed the values measured in samples from this depth range, we assume that groundwater flow has occurred in this region, which has contributed to the high apparent thermal conductivity by advective heat transport. Therefore, we used our first model to obtain the inlet and outlet tube temperatures at this depth range. Their difference was approximately $0.3 \mathrm{~K}$ at $80-90 \mathrm{~m}$ depth and decreased with increasing depth. We used the $0.3 \mathrm{~K}$ difference in the second model by assuming inlet and outlet temperatures of 7.0 and $7.3{ }^{\circ} \mathrm{C}$, respectively. For the temperature of the surrounding soil at approximately $85 \mathrm{~m}$ depth, we assumed $10^{\circ} \mathrm{C}$. The temperature distribution for the underground was determined by a numerical model. In this model, we used a typical heat production rate of $0.6 \mathrm{~W} \mathrm{~m}^{-2}$ on the bottom and the paleontological heat increased over the last 60 years (Mann et al. 2008) as the top boundary conditions, respectively.

\section{Simulation of the temperature distribution in a horizontal plane around the bhe Model set-up}

Here, we study the influence of groundwater flow on the temperature distribution by simulating a 2D horizontal cross section of the borehole heat exchanger. The model area consists of $247 \times 247$ cells and is $18 \mathrm{~m} \times 18 \mathrm{~m}$ in size. We refined the discretization to

Table 1 Parameters used for the numerical simulation of the working fluid temperature

\begin{tabular}{llllll}
\hline Units & $\begin{array}{l}\text { Thermal } \\
\text { conductivity } \\
{\left[\mathbf{W ~ m}^{-1} \mathbf{K}^{-1}\right]}\end{array}$ & $\begin{array}{l}\text { Volumetric } \\
\text { heat capacity } \\
{\left[\mathbf{M}^{-1} \mathbf{~ m}^{-\mathbf{3}}\right]}\end{array}$ & Permeability $\left[\mathbf{m}^{\mathbf{2}]}\right.$ & Porosity $[-]$ & Temperature $\left[{ }^{\circ} \mathbf{C}\right]$ \\
\hline Ground & $1.2-3.0$ & 2.3 & $3 \times 10^{-11}$ & $0.200-0.300$ & 10.0 \\
BHE cement & 2.0 & 1.0 & $1 \times 10^{-19}$ & 0.010 & 10.0 \\
Pipe & 0.3 & 4.0 & $1 \times 10^{-20}$ & 0.001 & Calculated \\
\hline
\end{tabular}




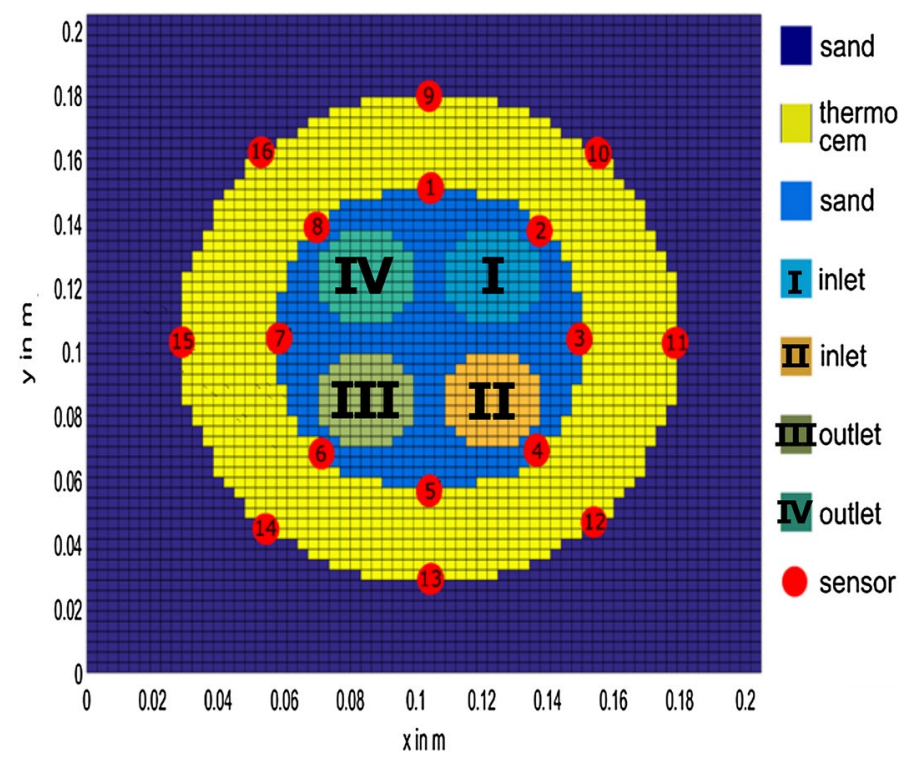

Fig. 3 Schematic top view of the fine discretized part of the 2D model with the double U-tube BHE in the middle. The property zones are color-coded and differ in heat conductivity, heat capacity, porosity and permeability (see Table 2 for the values). The two inlet tubes (I and II) are shown in orange and light blue, and the two outlet tubes (III and IV) in light green and green

Table 2 Parameters used for the numerical simulation of the temperature distribution around the BHE

\begin{tabular}{|c|c|c|c|c|c|}
\hline Units & $\begin{array}{l}\text { Thermal } \\
\text { conductivity } \\
{\left[\mathrm{W} \mathrm{m}^{-1} \mathrm{~K}^{-1}\right]}\end{array}$ & $\begin{array}{l}\text { Volumetric } \\
\text { heat capacity } \\
{\left[\mathrm{MJ} \mathrm{K}^{-1} \mathrm{~m}^{-3}\right]}\end{array}$ & Permeability $\left[\mathrm{m}^{2}\right]$ & Porosity [-] & $\begin{array}{l}\text { Temperature } \\
{\left[{ }^{\circ} \mathrm{C}\right]}\end{array}$ \\
\hline Ground & 2.8 & 2.0 & $3 \times 10^{-11}$ & 0.330 & 10.0 \\
\hline Thermocem & 2.0 & 1.0 & $1 \times 10^{-19}$ & 0.010 & 10.0 \\
\hline Inlet tubes & 0.3 & 4.0 & $1 \times 10^{-20}$ & 0.001 & 7.0 \\
\hline Outlet tubes & 0.3 & 4.0 & $1 \times 10^{-20}$ & 0.001 & 7.3 \\
\hline
\end{tabular}

$0.32 \mathrm{~cm}$ in the borehole section. Figure 3 shows a scheme of the fine discretized part of the model. We assumed a standard PE-100 double u-pipe BHE of $100 \mathrm{~m}$ depth and a borehole of $150 \mathrm{~mm}$ diameter. The inlet tubes and outlet tubes have a diameter of $32 \mathrm{~mm}$ each. Corresponding to Fig. 1, the inlet tubes are marked with a cross (in Fig. 3: I and II), while the outlet tubes are marked with a dot (in Fig. 3: III and IV). A BHE is normally back-filled with a concrete suspension with a thermal conductivity of approximately $2.0 \mathrm{~W} \mathrm{~m}^{-1} \mathrm{~K}^{-1}$ to reduce thermal resistivity to the ground. According to the data provided by the EGRT, the simulated surrounding soil has a thermal conductivity of $2.6 \mathrm{~W} \mathrm{~m}^{-1} \mathrm{~K}$. All parameters used in the numerical simulation for the horizontal 2D model are shown in Table 2.

\section{Results}

In our model, we assumed a depth of $85 \mathrm{~m}$ in a $100 \mathrm{~m} \mathrm{BHE}$, with a soil temperature of $10^{\circ} \mathrm{C}$ at this depth. The temperatures at the inlet tubes and outlet tubes are set to 7.0 and $7.3{ }^{\circ} \mathrm{C}$, respectively. Thus, the temperature difference of the tubes is $0.3 \mathrm{~K}$, as obtained 

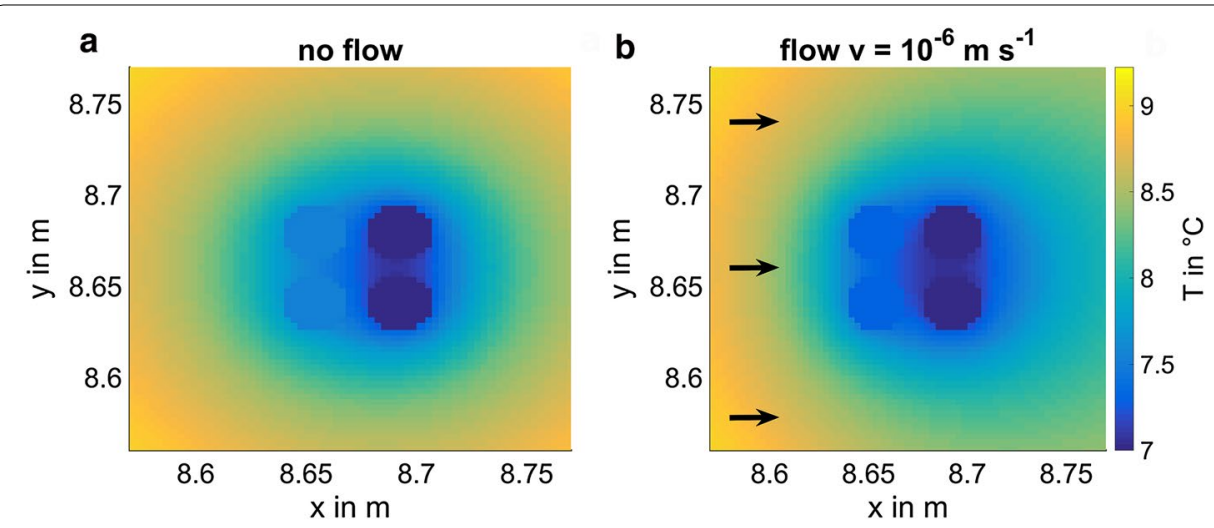

Fig. 4 Temperature distribution at the BHE region without groundwater flow (a) and with groundwater flow at $10^{-6} \mathrm{~m} \mathrm{~s}^{-1}\left(\mathrm{ca} .31 \mathrm{~m} \mathrm{a}^{-1}\right)$, both under stationary conditions. The black arrows in (b) indicate the groundwater flow direction

from the numerical simulations in the previous chapter. With this model, we study the influence of groundwater flow on the temperature distribution, especially on the temperature at the sensor positions shown in Fig. 1. We consider three different groundwater flow velocities of $10^{-6} \mathrm{~m} \mathrm{~s}^{-1}, 10^{-7} \mathrm{~m} \mathrm{~s}^{-1}$, and $10^{-8} \mathrm{~m} \mathrm{~s}^{-1}$ and vary the flow direction from $0^{\circ}$ (W direction) to $180^{\circ}$ (E direction) in steps of $22.5^{\circ}$.

In Fig. $4 \mathrm{a}$ and $4 \mathrm{~b}$, we show the simulated temperature distributions for the BHE region at $10^{-6} \mathrm{~m} \mathrm{~s}^{-1}$ (compared to Fig. 3) without and with groundwater flow, respectively. The black arrows in Fig. 4b indicate the flow direction.

Under stationary conditions, the model with groundwater flow as advective heat transport is dominant (soil temperature is $10^{\circ} \mathrm{C}$ ) and is on average warmer than the one without flow. From the results in Fig. 4, groundwater flow appears to only minutely change the temperature at the inner ring sensors labeled 1-8 (see Figs. 1 and 3). However, the inner ring is essential for determining the sensor's position relative to the BHE tubes. As the double U-tube heat exchanger is asymmetrical, the temperature shift resulting from the BHE layout has to be taken into account. Depending on the groundwater's angle of incidence, the distorted temperature distribution differs with the relative position of the inlet tubes and outlet tubes, provided that they have a temperature difference. The influence of groundwater flow on the inner and outer ring temperatures will be discussed in the following section.

We performed a numerical simulation to investigate the groundwater influence on the temperature distribution of a BHE. In Fig. 5, the calculated temperature data at the sensor positions of the inner ring (a) and the outer ring (b) are shown for three different groundwater flow rates $\left(v=10^{-6} \mathrm{~m} \mathrm{~s}^{-1}, 10^{-7} \mathrm{~m} \mathrm{~s}^{-1}\right.$, and $10^{-8} \mathrm{~m} \mathrm{~s}^{-1}$ and for no-flow conditions). The BHE inlet tube and outlet tube temperatures had a significant impact on the inner ring temperatures. According to the calculated temperatures at the inlet tubes and outlet tubes in Fig. 2, we expect a temperature difference of $0.3-0.4{ }^{\circ} \mathrm{C}$ for the inlet tube and the outlet tube at the depth range of $80-90 \mathrm{~m}$. Here, we used $7.3^{\circ} \mathrm{C}$ for the inlet tube temperature and $7.0{ }^{\circ} \mathrm{C}$ for the outlet tube temperature, respectively. In this example, both inlet tubes were near sensors 2 and 4, while the outlet tubes were in the vicinity of sensors 6 and 8. Sensors 1 and 5 monitored the inner ring, and sensors 9 and 

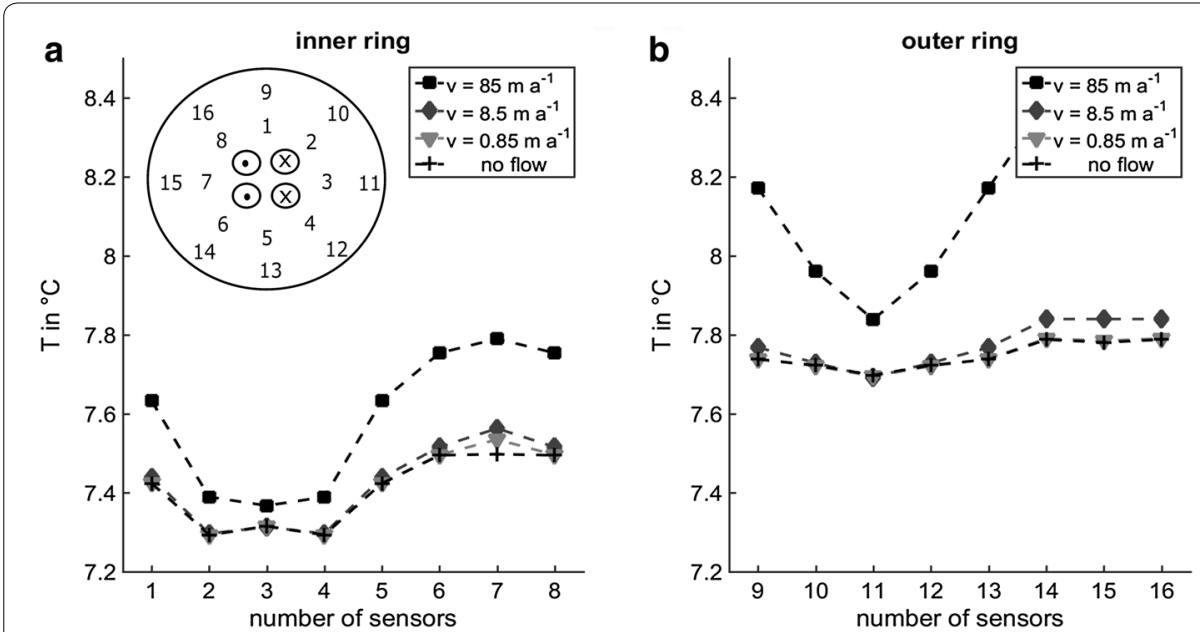

Fig. 5 Simulated temperature data at sensor positions 1-8 of the inner ring (a) and 9-16 of the outer ring (b). The sketch in (a) in the right top corner shows the BHE tubes with sensors

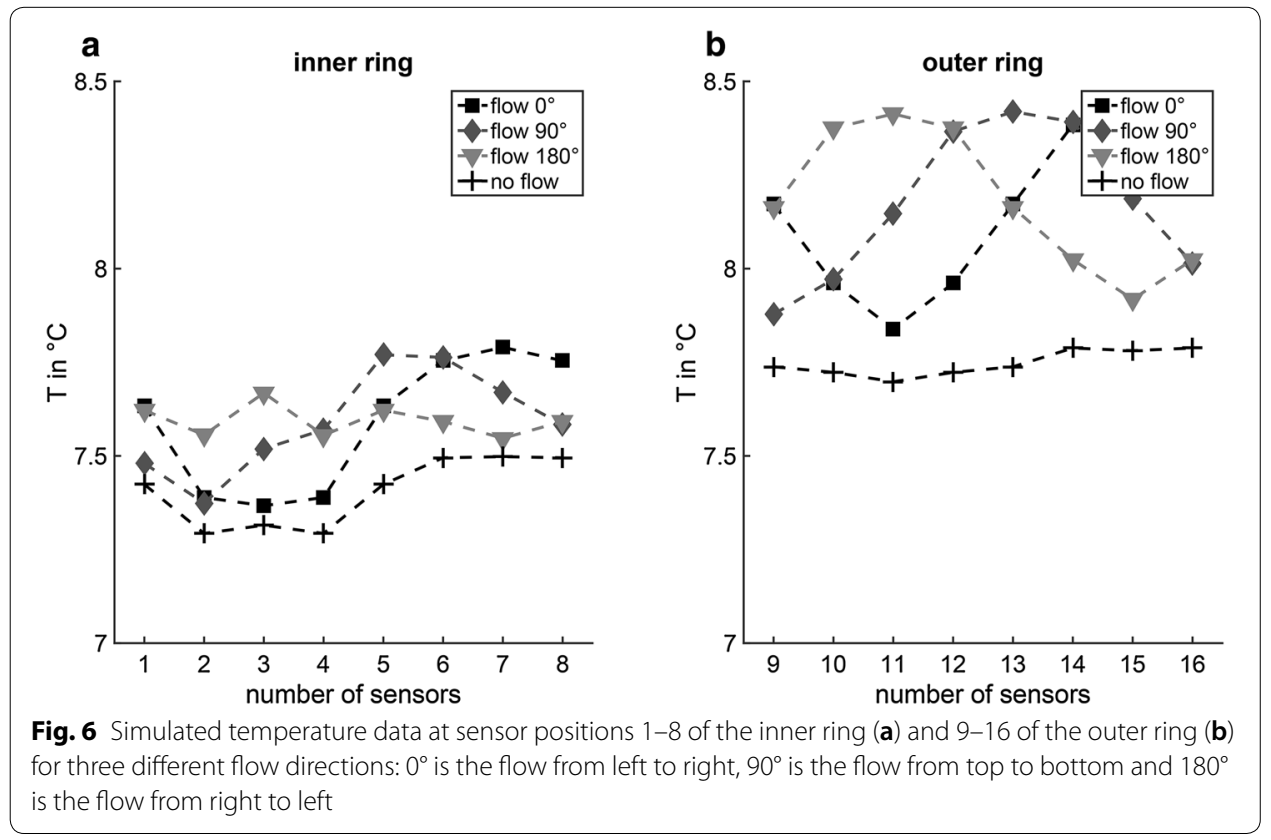

13 showed equal temperatures, respectively, as expected for this set-up. The temperature increased rapidly with higher flow rates as heat was transported by advection in the groundwater. Compared to the no-flow condition, we observed a significant temperature change at the outer sensors at flow rates higher than $10^{-7} \mathrm{~m} \mathrm{~s}^{-1}$. Thus, the outer ring can be used to detect groundwater flow, and the inner ring can be used to determine the orientation of the TSM relative to the BHE inlet and outlet tubes. This is important as the position of the TSM relative to the inlet tube and outlet tubes most likely changed during the insertion of the BHE into the ground. Additionally, the temperature at the inner ring was influenced by advective heat transport at a flow velocity of $85 \mathrm{~m} \mathrm{a}^{-1}$ (see Fig. 5). 
In Fig. 6, we show numerically calculated temperatures influenced by groundwater flow from three different flow directions for the inner (a) and outer ring (b) sensor positions. We varied the groundwater flow directions: $0^{\circ}, 90^{\circ}$ and $180^{\circ}$ correspond to flow from left to right, from top to down, and from right to left in Fig. 1, respectively. Assuming a relatively high flow rate of $10^{-6} \mathrm{~m} \mathrm{~s}^{-1}$, the outer ring sensors show a strong correlation with the groundwater flow direction. Changing the flow direction, the calculated temperatures for the outer ring sensors shift as expected. However, the temperatures of the inner sensors are mostly influenced by the temperature of the inlet and outlet tubes and show a much smaller temperature spread. The interpretation of the inner ring temperature distribution is very difficult, as it is influenced by the inlet and outlet positions, their temperatures and the groundwater flow rate.

\section{Conclusions of the numerical study}

Groundwater flow as low as $10^{-7} \mathrm{~m} \mathrm{~s}^{-1}$ can be detected with the TSM consisting of two temperature sensor rings: an inner ring for detecting the orientation of the BHE tubes and an outer ring for detecting the groundwater-induced temperature changes. At flow rates of $10^{-6} \mathrm{~m} \mathrm{~s}^{-1}$, the temperature distribution at the outer ring differs strongly from that under no-flow conditions. Lower flow rates of approximately $10^{-7}$ $\mathrm{m} \mathrm{s}^{-1}$ cause temperature shifts of less than $0.1 \mathrm{~K}$. At a groundwater flow velocity of $10^{-6} \mathrm{~m} \mathrm{~s}^{-1}$, the flow direction can be easily resolved. The angular resolution depends mainly on the number of sensors installed on the outer ring. In our case, the angular separation is $45^{\circ}$, i.e., we can obtain flow directions with an accuracy of approximately $22.5^{\circ}$.

\section{Temperature sensor module experiments TSM prototype}

Encouraged by the introduced simulation results, we designed a TSM prototype for testing and proving the concept (Fig. 7). The TSM consists of digital temperature sensors allocated on a modular double ring system. We used the open source software Arduino IDE to control the sensors. Each module consists of three double ring levels allocated vertically on two tubes.

The TSM prototype frame is made up of two tubes. The frame is $40 \mathrm{~cm}$ long and has an outer diameter of $150 \mathrm{~mm}$ and an inner diameter of $90 \mathrm{~mm}$. For mounting purposes, the TSM is divided in two halves, which are equipped with holders for attaching the TSM to the BHE inlet and outlet tubes. The entire frame consists of PCA plastic for the following two reasons: (1) plastic is preferred to avoid disturbing the magnetic field sensors for the real TSM modules installed inside the BHE, and (2) material with low thermal conductivity is used to hinder the mutual influence of neighboring sensors. The measurement sensors are positioned horizontally on two rings attached to the inner and outer frame tubes (labeled 4 in Fig. 7). Each ring is equipped with eight sensors. The sensors and their electronic periphery are assembled on flex boards. We used digital ADT7240 semiconductor temperature sensors with a resolution of 16 bit [datasheet ADT7240 (2017)]. They are capable of resolving temperature in $0.0078 \mathrm{~K}$ steps. We used open source Arduino software (based on 


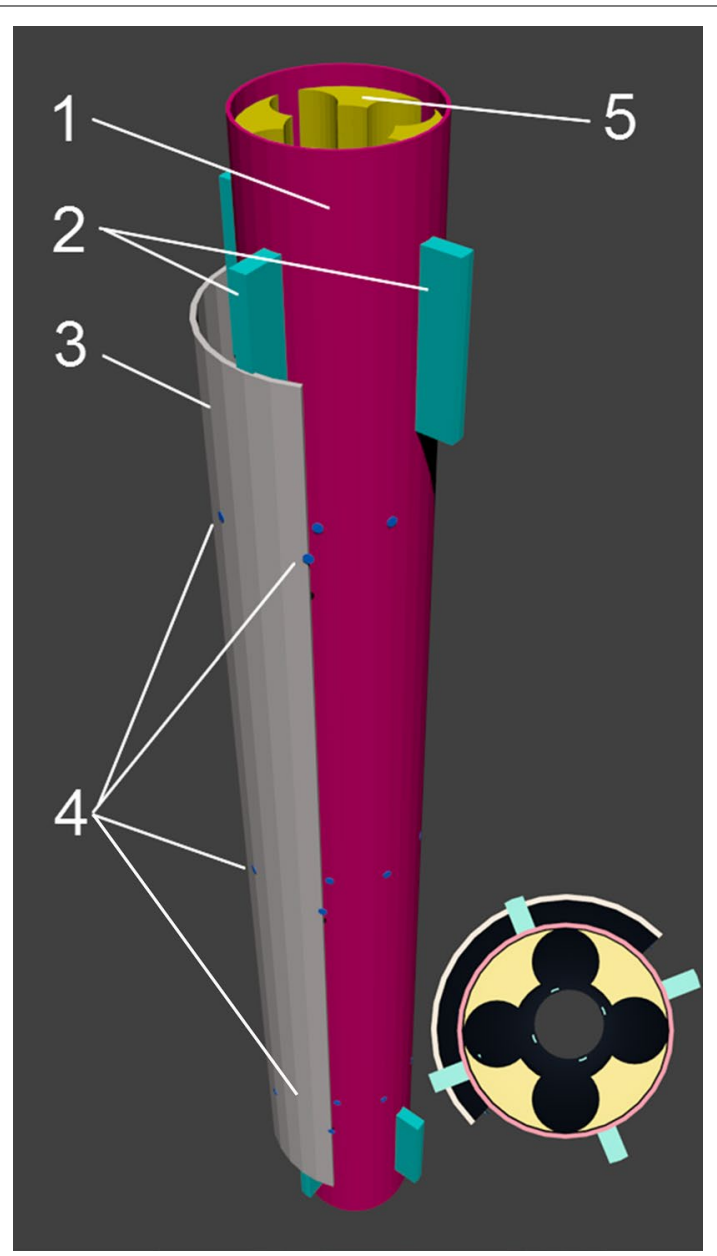

Fig. 7 Temperature sensor module (TSM) with three temperature sensor (4) ring levels. The TSM is mounted via the yellow spacers (5) to the inlet and outlet tubes of the BHE. The TSM main tube (red) is $1 \mathrm{~m}$ long. The blue spacers (2) ensure a constant distance between the inner (red) and the outer tubes (gray) and thus between the inner and outer ring temperature sensors (4)

$\mathrm{C}++)$ and hardware for programming and reading the digital temperature sensors. The data, which are collected via an Arduino $\mu$ Controller, are transmitted and stored via ethernet to a database for further processing. For more technical details about the TSM, see Michalski and Klitzsch (2017). We calibrated the sensors relative to one master sensor with an accuracy of approximately $40 \mathrm{mK}$ using an insulated water bath connected to a thermostat with an accuracy of $10 \mathrm{mK}$.

\section{Sandbox experiment}

We tested the TSM prototype in a sandbox experiment. For that, we installed a BHE model together with the TSM prototype in the sandbox, which can handle water flow at a constant rate. Figure 8 shows the experimental set-up. The sand-filled cubic box has an edge length of $80 \mathrm{~cm}$ and two water tanks attached on opposite sides. The tanks are hydraulically connected to the box via felt-covered, perforated walls. They enable a hydraulic gradient across the sandbox, and thus, water flows through it. 


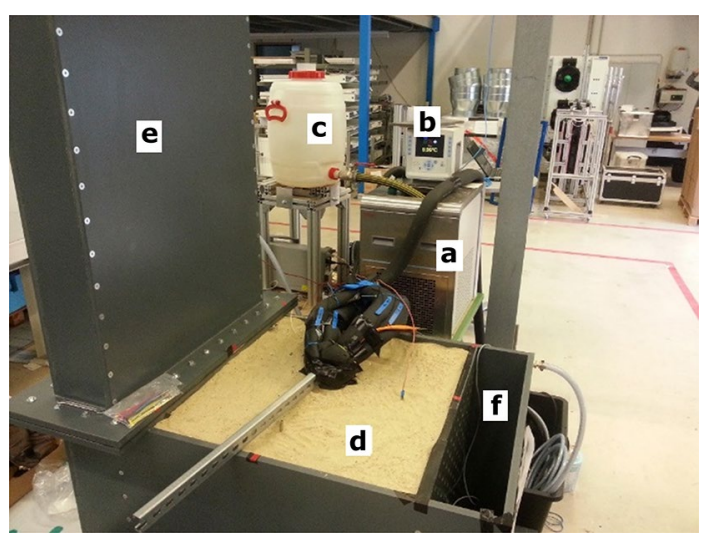

Fig. 8 Experimental set-up for testing the TSM prototype under flow conditions. a-c are the devices used to simulate the BHE operation: the thermostat, its controlling unit and a small backup water reservoir, respectively. The sandbox (d) contains the BHE model with the TSM prototype attached to it. Water flow through the sandbox is driven by the hydraulic gradient between the two water tanks (e) and (f)

The TSM sits in the center of the sandbox and is attached to four tubes. They represent the two inlet tubes and outlet tubes of the BHE and are connected to temperaturecontrolled water reservoirs. The latter provides stable temperatures, with an accuracy of $0.01{ }^{\circ} \mathrm{C}$, and the attached pump enables volume flow rates of $0.5 \mathrm{l} \mathrm{s}^{-1}$. At the beginning of the experiment, the sand and the water in the side tanks were at the laboratory temperature, which varied between 20 and $22{ }^{\circ} \mathrm{C}$ during the experiment. The TSM was oriented to allow (ground)water to flow from sensor 1 to sensor 5.

With this set-up, we performed experiments at different flow rates through the sandbox, i.e., we simulated different groundwater flow velocities. For this, we created a hydraulic gradient between the two opposite water tanks by constantly pumping water from one tank into the opposite tank. Thus, we were able to establish constant flows at certain rates, i.e., certain constant hydraulic gradients. For all experiments, we monitored the temperature distribution using the TSM. For the first experiment, the whole sandbox was at ambient temperature and no (ground)water flow through the sandbox was established. After pumping cool water through the BHE model, we monitored the temperature decrease until we reached steady state conditions. Subsequently, we turned the pump off and monitored the temperature increase in the sandbox. Afterwards, we repeated the experiment at different groundwater flow rates. We enforced the groundwater flow by hydraulic heads of 15,7 , and 3.5 in the water tanks adjacent to the sandbox. We started with a hydraulic head of $15 \mathrm{~cm}$. After reaching stationary conditions, we decreased the hydraulic head first to $7 \mathrm{~cm}$ and second to $3.5 \mathrm{~cm}$. For the experiments with and without (ground)water flow, we cooled the working fluid of the BHE down to 10 and $15^{\circ} \mathrm{C}$, respectively.

Prior to the flow experiment with temperature monitoring, we performed a tracer test to determine the hydraulic conductivity of the sand in the box. For this experiment, we injected salt water into the source tank and measured the electrical conductivity in the sink tank. For the established hydraulic head of $12 \mathrm{~cm}$, we obtained a velocity of approximately $2 \times 10^{-5} \mathrm{~m} \mathrm{~s}^{-1}$ and thus a hydraulic conductivity of approximately $3 \times 10^{-4} \mathrm{~m}$ 
$\mathrm{s}^{-1}$ or a permeability of approximately $3 \times 10^{-11} \mathrm{~m}^{2}$, which we used for subsequent simulations.

\section{Comparison of experiments and numerical simulations}

We used the experiment without a hydraulic head, i.e., without (ground)water flow, to adjust the thermal properties of the sandbox model. From this, we obtained a thermal conductivity of approximately $2.8 \mathrm{~W} \mathrm{~m}^{-1} \mathrm{~K}^{-1}$ and a water heat capacity of $2 \mathrm{MJ} \mathrm{K} \mathrm{K}^{-1} \mathrm{~m}^{-3}$ for the filling material of the sandbox, medium-grained sand with a porosity of approximately $30 \%$. These values match those obtained from laboratory measurements of sand samples. For the Thermocem ${ }^{\circledR}$ cement, which is in between the two TSM tubes, we used a porosity of $10 \%$ and assumed, as plastic tubes enclose it, a very low permeability of $10^{-19} \mathrm{~m}^{2}$. Its thermal conductivity and heat capacity were $2 \mathrm{~W} \mathrm{~m}^{-1} \mathrm{~K}^{-1}$ and $2 \mathrm{MJ} \mathrm{K}^{-1} \mathrm{~m}^{-3}$, respectively. Its thermal conductivity strongly influenced the temperature gradient of our measurement. Thus, Thermocem ${ }^{\circledR}$ mainly causes the temperature difference between the inner and the outer sensor rings. Those results were inserted into a numerical 2D model of the TSM with a BHE, as described in "Model set-up" subsection.

In Fig. 9, we show the experiment together with the simulation results for the cooling phase where the BHE was turned on (Fig. 9a) and for the relaxation phase after the BHE was turned off (Fig. 9b). For simplicity and because of the model symmetry, we show the temperature for only one inner (black) and one outer ring sensor (gray). The numerical model mirrors the measured the temperature variation well. The simulated and measured temperatures slightly deviate from each other for only the fast temperature changes. The temperature fluctuations, which were under steady state conditions (Fig. 9a), were caused by the variation in the ambient temperature in the laboratory. As we also monitored the ambient temperature, we considered it a time-dependent
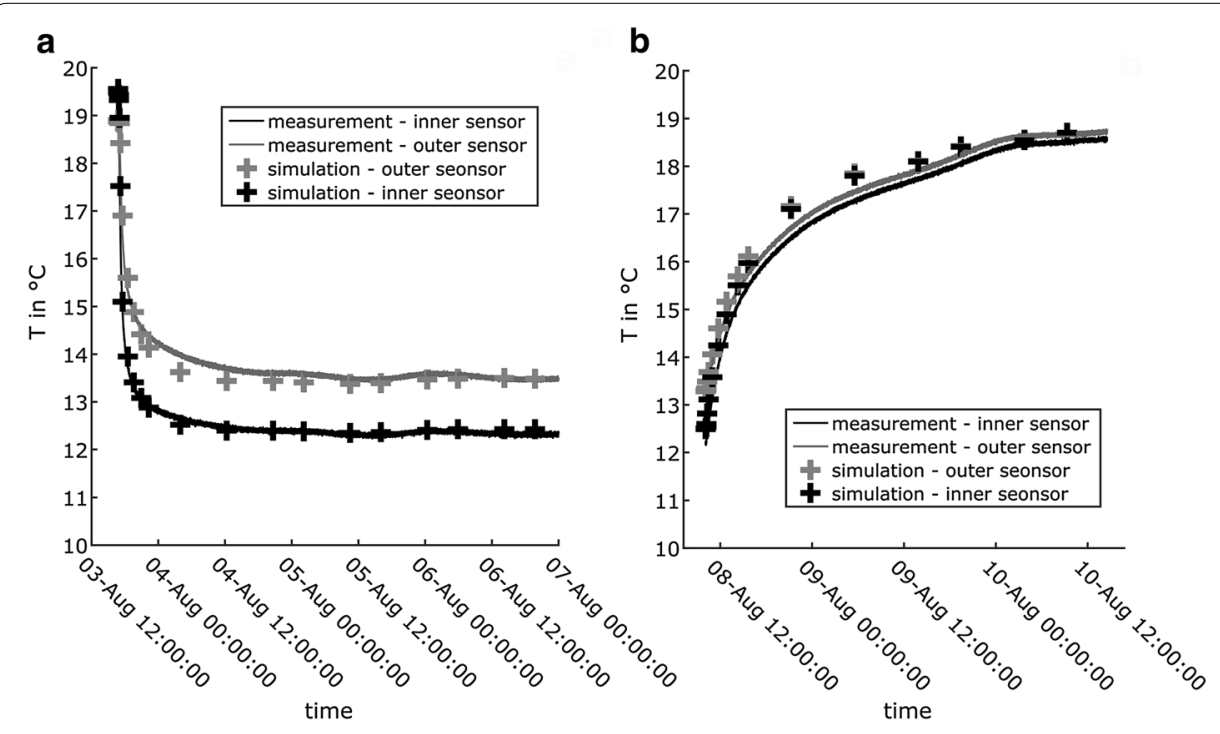

Fig. 9 Temperature development during the cooling (a) and the relaxation phase (b) at the inner (black) and outer rings (gray) of the TSM for the sandbox experiment without (ground) water flow. The BHE fluid had a temperature of $10^{\circ} \mathrm{C}$, while the ambient temperature in the laboratory was approximately $20^{\circ} \mathrm{C}$ 

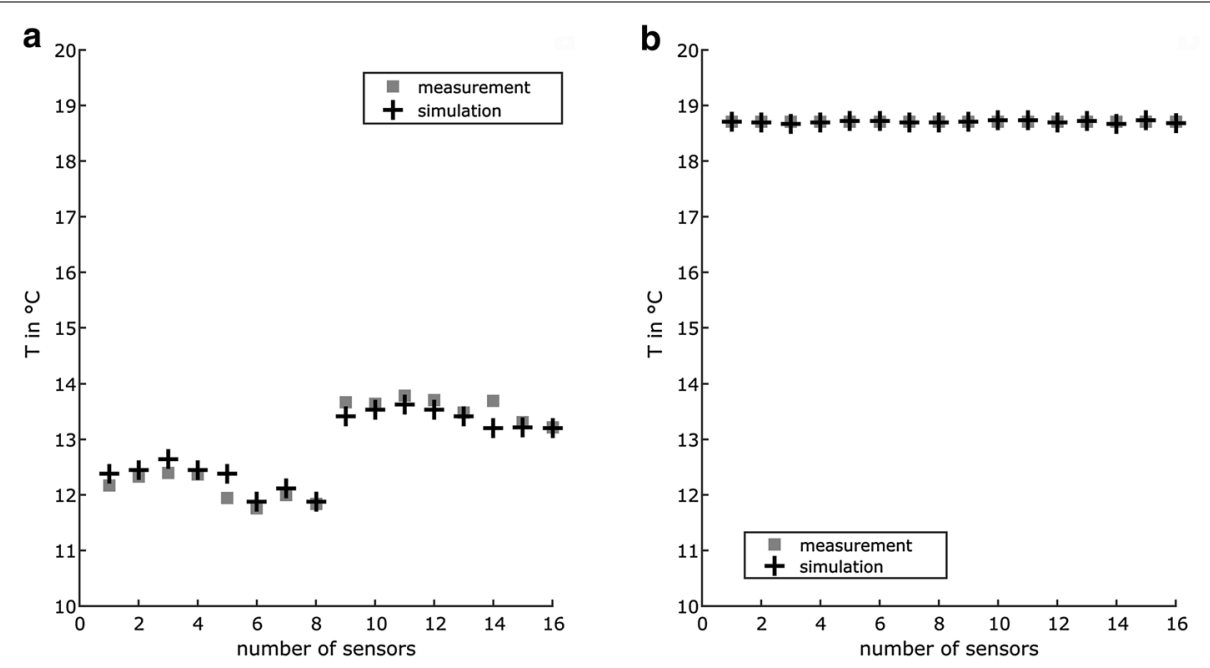

Fig. 10 Simulated (plus sign) and measured temperatures (white square) under steady state conditions of the cooling (a) and the relaxation phases (b) of all TSM sensors for the sandbox experiment without (ground) water flow

boundary condition in our simulation. The ambient temperature variations of approximately $1 \mathrm{~K}$ caused fluctuations at the TSM of approximately $0.1 \mathrm{~K}$.

In Fig. 10, we show the results of the same experiment under steady state conditions for the cooling (a) and the relaxation phases (b) for all temperature sensors. Again, we compared the measured and the simulated temperatures. In the cooling phase (Fig. 10a), the temperatures of the inner ring sensors $1-8$ were below those of the outer ring sensors $9-16$ because of their proximity to the heat sink. The numerical simulation and experimental data match quite well, although the simulated and measured temperatures slightly deviate for the inner ring sensors 3 and 5 and for the outer ring sensors 9 and 14 . A deviation can occur for several reasons, but we propose errors in the sensor position as the major cause. Especially for the inner sensors, a small deviation in the position, and hence in the distance between the sensors and the BHE tubes, can cause temperature differences of up to $0.3 \mathrm{~K}$. The temperatures measured at the inner sensors strongly depend on their relative positions to the in- and out-flow tubes. Thus, the inner ring temperatures can be used to determine the position of the inlet and outlet tubes of the BHE.

Figure 10b shows the measured and simulated steady state temperatures of the relaxation phase after turning the BHE off. Here, the results of the simulations are in good agreement with the experimental data. As expected, the inner and outer ring sensors have the same temperature, which is close to the laboratory temperature.

Finally, we tested the TSM in the sandbox by establishing water flow from one side to the other side of the box. The experiment started at a hydraulic head of $15 \mathrm{~cm}$. After reaching a constant temperature level, we subsequently reduced the hydraulic head to 7 and $3.5 \mathrm{~cm}$. The water reservoir temperature for the BHE was $15^{\circ} \mathrm{C}$. However, due to heating effects from the environment, the resulting working fluid temperatures in the inlet and outlet tubes of the BHE model were slightly different: 15.45 and $15.05{ }^{\circ} \mathrm{C}$ for the inlets and 16 and $15.15^{\circ} \mathrm{C}$ for the outlets. We measured the temperatures at the top 

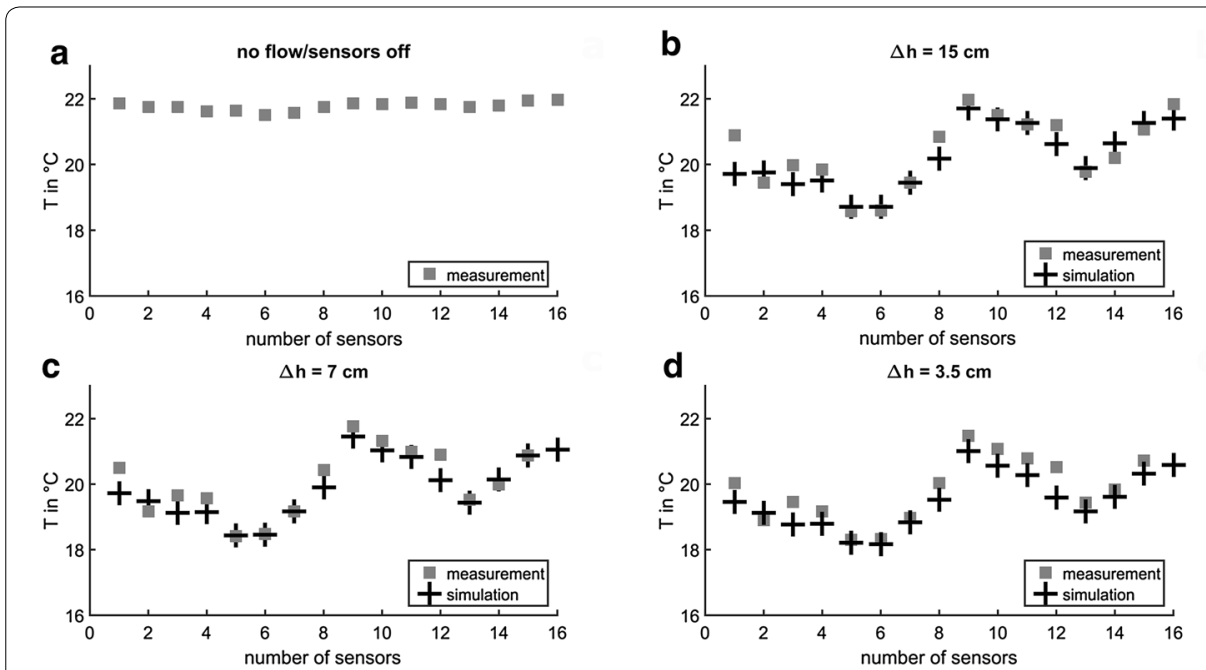

Fig. 11 Simulated (plus sign) and measured (white square) temperatures at the inner and outer ring sensors under steady state conditions (a) for no (ground)water flow and with (ground)water flow enforced by hydraulic heads of $\mathbf{b} 15 \mathrm{~cm}, \mathbf{c} 7 \mathrm{~cm}$ and $\mathbf{d} 3.5 \mathrm{~cm}$

of the BHE tubes using surface PT-100 temperature sensors. These temperature values were used as inputs for the numerical simulations. Moreover, the water, constantly pumped from one tank to the other to establish water flow through the box, was heated during the experiment by approximately $1 \mathrm{~K}$ due to the heat introduced by the pump. Again, we considered the temperature change in the numerical simulation by adapting the temperature boundary conditions.

We ran the experiment for $9 \mathrm{~h}$. Unfortunately, sensor 16 broke during the experiment. Therefore, we cannot show temperatures from this sensor at the hydraulic heads of 7 and $3.5 \mathrm{~cm}$. Figure 11 shows the numerically calculated and the measured TSM temperatures under the steady state conditions for the different experiments: initial temperatures before turning on the BHE and b-d TSM temperatures at constant hydraulic heads of 15,7 and 3.5 , respectively.

Apart from those recorded by sensors 1 and 8 of the inner ring, the simulation matched the measured temperatures well. We attribute the deviation of these sensors to water seeping into the joint between the two parts that construct the TSM. Such water infiltration would primarily affect sensors 1 and 8 , which are next to the joint.

The other sensors showed good agreement between measurement and simulation, whereas the recorded temperature pattern looks very similar for the three different hydraulic heads. The inner ring sensor temperatures mainly depend on the temperatures of the inlet and outlet tubes. Hence, they should look similar and can be used to determine the relative orientation of the TSM to the BHE. The outer ring sensor temperatures were higher and showed greater variability than the inner ring sensors. However, the effect of the decreasing hydraulic head on the temperatures was lower than predicted: With a decreasing hydraulic head, the measured and simulated temperature differences in the flow direction (sensor pairs $1-5$ and $9-13$ ) decreased by $\approx 0.2 \mathrm{~K}$ at the outer ring and by $\approx 0.4 \mathrm{~K}$ at the inner ring. The temperature change at the inner ring is due to the permeable inner backfilling material. We filled the interior of the TSM prototype with sand for easier assembly and disassembly of the TSM prototype to the BHE tubes. A 


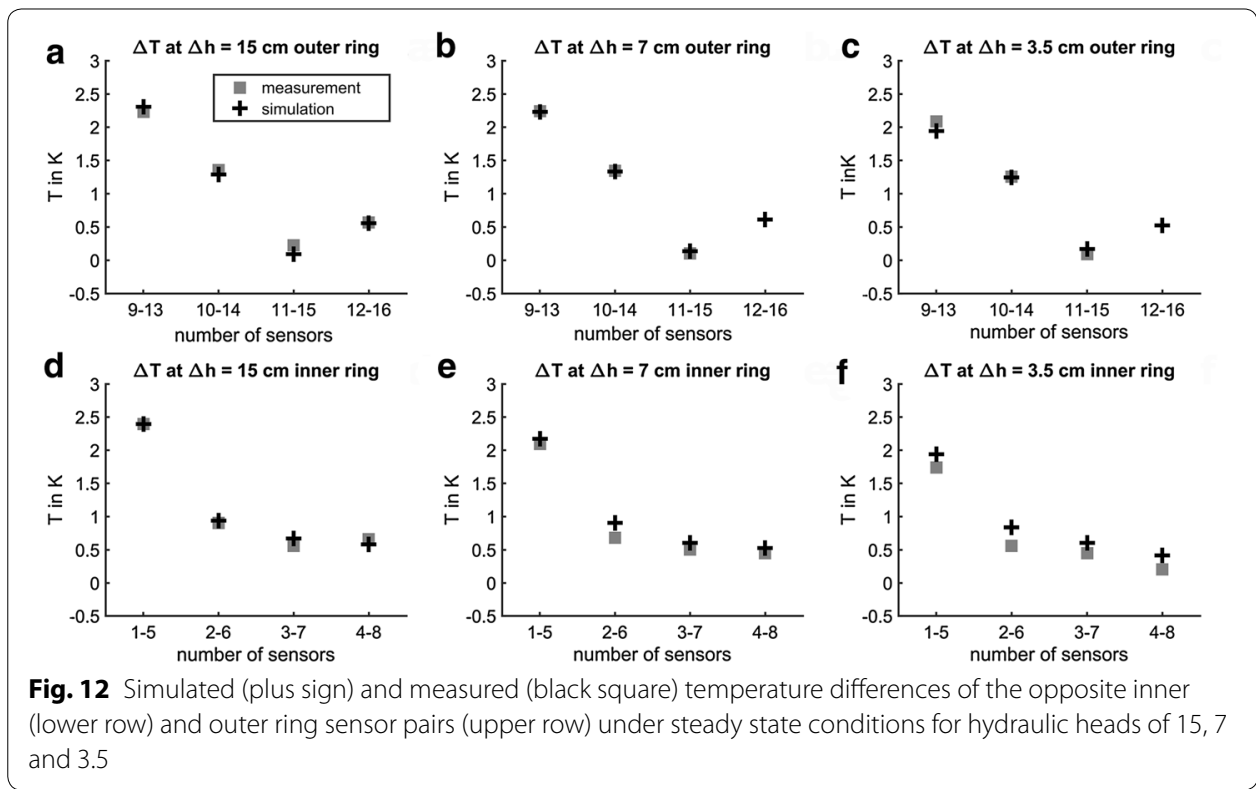

completely cement-filled TSM cannot be disassembled and separated from the BHE tubes. Hence, water flow affected the interior sensors of the TSM prototype.

Figure 12 shows the temperature difference between opposite sensor pairs a-c for the outer ring and $\mathrm{d}-\mathrm{f}$ for the inner ring for hydraulic heads of 15,7 and 3.5, respectively. The water flows from sensor 1 to 5 (inner ring) or from sensor 9 to 13 (outer ring). Caused by the advective heat transport of the water, the latter pairs have the highest temperature differences for both the measured and the simulated data (Fig. 12). Thus, the experiment confirms the ability of the TSM to detect groundwater flow and to deduce its direction from the monitored temperatures.

We ascribe the differences between measured and simulated temperatures to the inaccuracy of the numerical model. We have not included the casing of the sensor boards or the protection films in the numerical simulation, as the dimensions of those parts are at or below the size of the grid cells. They affect not only the thermal properties of the TSM but also the position of the sensors. Those parts influence the apparent thermal conductivities and, due to their fabrication, cause displacement of the sensors from ideal cylindrical coordinates. The displacement of a sensor by $3.2 \mathrm{~mm}$, which corresponds to the cell size of the model, causes a temperature change of up to $0.2 \mathrm{~K}$ in the numerical simulation.

Apart from those recorded by sensor pair 1-5 of the inner sensors, the simulated and measured temperature differences agree well. As described previously, water seeping into the joint of the two TSM halves probably caused the large difference between sensors 1 and 5 .

\section{Summary and conclusions}

We presented a new temperature-sensing method to derive groundwater flow from temperature distribution measurements near the BHE. First, we jointly simulated heat transport and groundwater flow in a 2D model of a BHE to derive the temperature 
resolution required for detecting groundwater flow. For that, we used groundwater flow rates of $10^{-6} \mathrm{~m} \mathrm{~s}^{-1}, 10^{-7} \mathrm{~m} \mathrm{~s}^{-1}$ and $10^{-8} \mathrm{~m} \mathrm{~s}^{-1}$. Subsequently, we used them in the 2D BHE model to simulate the temperature distribution near the BHE with and without flow, revealing that both rings are necessary to interpret the temperature distribution. While groundwater flow affects the outer ring temperatures, the inner ring temperatures mainly depend on the distances between the sensors and the inlet tubes or outlet tubes. Hence, the position of the tubes and their temperatures have large impacts on the inner ring temperatures. They provide the TSM orientation relative to the BHE tubes, which is essential because of the asymmetrical temperature distribution of the double U-tube BHE. Our simulations show that the flow direction can be resolved at an angle of $22.5^{\circ}$. Under no-flow conditions, the asymmetry of the BHE slightly influences the outer ring temperature distribution, but a flow velocity of $10^{-6}$ $\mathrm{m} \mathrm{s}^{-1}$ clearly changes it, i.e., such a groundwater flow rate can be easily detected. For the lowest flow velocity detectable with the TSM, we obtain $10^{-7} \mathrm{~m} \mathrm{~s}^{-1}$ if we assume a temperature resolution of $0.1 \mathrm{~K}$ for the temperature difference of opposing sensors. Hence, in the case of small flow velocities, the contribution of the BHE pipe arrangement has a larger impact on the temperature distribution of the outer ring sensors (Fig. 5b).

To test the approach, we designed a TSM prototype and applied it in a sandbox experiment, which contained a BHE model. There, we monitored the TSM temperatures without and with groundwater flow after starting and stopping the BHE operation. The experiments confirm the detectability of groundwater flow at relatively high flow rates on the order of $10^{-5} \mathrm{~m} \mathrm{~s}^{-1}$. Furthermore, we also observed the sensitivity of the outer ring temperatures to flow direction. Due to the design of the TSM with eight temperature sensors per ring, we postulate an angular resolution of $22.5^{\circ}$ with an accuracy of $\pm 11.25^{\circ}$. Unfortunately, we could not confirm the angular resolution in the sandbox experiment as the experimental set-up allowed only one flow direction. Even though the simulations show that we meet the directional accuracy of $\pm 11.25^{\circ}$, we expect a decreasing accuracy with decreasing flow velocity for the real application of the TSM.

In general, the simulations match the observations but also partially deviate. We attribute the deviations between measurement and simulation to the complexity of the TSM set-up, which was not fully considered in our numerical model.

In the following project step, TSMs will be installed within a real BHE at depths of interest between 50 and $100 \mathrm{~m}$. This will provide the possibility for testing the TSM under real conditions.

\section{Authors' contributions}

Both authors contributed according to their respective areas of expertise. AM designed and constructed the temperature sensor module. He set up the numerical models and performed the numerical simulation and experiments. NK suggested the measuring method and helped analyzing the results. He drafted parts of the manuscript. Both authors read and approved the final manuscript. 
Competing interests

The authors declare that they have no competing interests.

Availability of data and materials

The datasets supporting the conclusions of this article are available in the PANGAEA repository, https://doi.panga ea.de/10.1594/PANGAEA.887260.

\section{Consent for publication}

Not applicable.

Ethics approval and consent to participate

Not applicable.

\section{Funding}

This work is funded by the German Federal Ministry of Economics and Energy (BMWi) under the Grant 03ET1022A.

\section{Publisher's Note}

Springer Nature remains neutral with regard to jurisdictional claims in published maps and institutional affiliations.

Received: 12 March 2018 Accepted: 30 July 2018

Published online: 10 August 2018

\section{References}

ADT7240 datasheet, analog devices, digital temperature sensors. 2017. http://www.analog.com/media/en/technicaldocumentation/data-sheets/ADT7420.pdf. Accessed 1 Feb 2018.

Bear J. Dynamics of fluids in porous media. Illinois: Dover; 1988

Bergmann H. Über die Grundwasserbewegung am Filterrohr. Munich: GSF-Bericht R24; 1970.

Carslaw HS, Jaeger JC. Conduction of heat in solids. New York: Oxford University Press; 1959.

Claesson J, Eskilson P. Simulation model for thermally interacting heat extraction boreholes. Numer Heat Transfer. 1988;13:149-65.

Clauser C. Numerical simulation of reactive flow in hot aquifers: SHEMAT and processing SHEMAT. Heidelberg: Springer; 2003

Diao N, Li Q, Fang Z. Heat transfer in ground heat exchangers with groundwater advection. Int J Therm Sci. 2004;43(12):1203-11.

Fütterer J, Constantin A. Energy concept for the E.ON ERC main building. 49th ed. Aachen: E.ON Energy Research Center; 2014.

Fütterer J, Constantin A, Müller D. An energy concept for multifunctional buildings with geothermal energy and photovoltaic. In: proceedings CISBAT (Cleantech for sustainable buildings from nano to urban scale) 2011. Lausanne: Ecole Polytechnique Fédérale de Lausanne; 2011. p. 697-702.

Guaraglia DO, Pousa JL. Introduction to modern instrumentation for hydraulics and environmental sciences. Berlin: De Gruyter; 2014

Hecht-Mendez J, de Paly M, Beck M, Bayer P. Optimization of energy extraction for vertical closed-loop geothermal systems considering groundwater flow. Energy Convers Manage. 2013;66:1-10.

Heidinger P, Fabritius A, Heinemann B, Dornstädter J (2004) EGRT_Enhanced Geothermal Response Tests, in: Die neue Rolle der Geothermie, Tagungsband GTV, 5. Symposium Erdgekoppelte Wärmepumpen, Landau.

Incropera FP, Bergman TL, Lavine AS, DeWitt DP. Fundamentals of heat and mass transfer. 7th ed. Hoboken: Wiley; 2011.

Klotz D (1977). Berechnung der Filtergeschwindigkeit einer Grundwasserströmung aus Tracerverdünnungsversuchen in einem Filterpegel.- GSF-Bericht R 149: 45 S., 24 Abb., 8 Tab.; GSF-Gesellschaft für Strahlen- und Umweltforschung $\mathrm{mbH}$, München.

Lazzari S, Priarone A, Zanchini E. Long-term performance of borehole heat exchanger fields with groundwater movement. In: COMSOL Conference, 2010. Paris: Elsevier; 2010. p. 1-10.

Luo J, Rohn J, Xiang W, Bayer M, Priess A, Wilkmann L, Steger H, Zorn R. Experimental investigation of a borehole field by enhanced geothermal response test and numerical analysis of performance of the borehole heat exchangers. Energy. 2015;84:473-84. https://doi.org/10.1016/j.energy.2015.03.013.

Mann ME, Zhang Z, Hughes MK, Bradley RS, Miller SK, Rutherford S, Ni F. Proxy-based reconstructions of hemispheric and global surface temperature variations over the past two millennia. Proc Nat Acad Sci. 2008;105(36):13252-7.

Michalski A, Klitzsch N (2017) Temperatursensormodul für Grundwasserströmungen, German Patent DE102016203865, 14.09.2017.

Morgenstern A (2005) Entwicklung einer Einbohrloch-Messsonde zur Bestimmung der horizontalen Fließparameter ohne Störung des Strömungsfeldes, Dissertation, Technische Universität Cottbus.

Pechnig R, Mottaghy D. Erstellung und Kalibrierung eines numerischen geothermischen Modells für das E.ON ERC Erdwärmesondenfeld. Aachen: Erläuterungsbericht der Geophysica Beratungsgesellschaft mbH; 2012.

Pitschel B. Bohrlochsonde zur Messung von Grundwasserströmungen auf der Basis der kontinuierlichen thermischen Anregung. Dissertation, TU Bergakademie Freiberg, Freiberg. 2001.

Rath V, Wolf A, Bücker M. Joint three-dimensional inversion of coupled groundwater flow and heat transfer based on automatic differentiation: sensitivity calculation, verification, and synthetic example. Geophys J Int. 2006;167:453-66.

Schön JH. Bohrlochgeophysikalische Messverfahren zur Untersuchung horizontaler Wasserbewegung in Brunnen und Bohrungen. In: Sonderdruck aus Beiträge zur Hydrogeologie, Bd. Bd. 47. Graz: Joanneum Research; 1996. p. 73-82. 
Schöttler M. Informationen zum GFV-Messsystem. Firmenschrift. 2000. http://www.phrealog.de/images/MediaCenter/ PHREALOG_Horizontale_Fliessmessung.pdf. Accessed 25 June 2018.

Wagner V, Bayer P, Kuebert P, Blum P. Numerical sensitivity study of thermal response tests. Renew Energy. 2012:41:245-53

Submit your manuscript to a SpringerOpen ${ }^{\circ}$ journal and benefit from:

- Convenient online submission

- Rigorous peer review

- Open access: articles freely available online

- High visibility within the field

- Retaining the copyright to your article

Submit your next manuscript at $\boldsymbol{\nabla}$ springeropen.com 